\title{
CARACTERIZAÇÃO HIDROGEOQUÍMICA DE ÁGUA SUBTERRÂNEA EM ÁREA DE INFLUÊNCIA DE FUTURAS INSTALAÇÕES DE USINAS HIDRELÉTRICAS - BACIA HIDROGRÁFICA DO RIO TAQUARI- ANTAS/RS, BRASIL
}

\author{
Rejane Maria Scopel, Elba Calesso Teixeira* e Raquel Barros Binotto \\ Fundação Estadual de Proteção Ambiental Henrique Luís Roessler, Rua Carlos Chagas, 55, 90030-020 Porto Alegre - RS
}

Recebido em 14/1/04; aceito em 15/10/04; publicado na web em 4/2/05

\begin{abstract}
HYDROCHEMICAL CHARACTERIZATION OF GROUNDWATERS IN PROJECTED HYDROELECTRIC POWER PLANT AREAS - TAQUARI-ANTAS BASIN/RS, BRAZIL. The identification and characterization of the hydrochemistry of the groundwaters has been done for seven wells. The sampling occurred during three bimonthly campaigns. The results classified the waters as of the calcium bicarbonated type for the majority of the samples, except for one well, whose composition is of the sodium bicarbonated type. The major ions found and how they determine the quality parameters are consistent with the reactions of mineral dissolution of the majority of volcanic rocks and the reactions with intrusion of alkaline rock in only one well. Anomalous values of nitrate in some wells alert to the impact of especially polluting sources at the time the reservoirs of the hydroeletric plant were formed.
\end{abstract}

Keywords: hydrochemistry; groundwater; hydroelectric power area.

\section{INTRODUÇÃO}

Usualmente, a água de superfície está suficientemente disponível para satisfazer os vários tipos de demanda de suprimento de água e onde isto não ocorre, as águas subterrâneas vêm sendo exploradas para este fim. As características químicas das águas de subsuperfície refletem os meios por onde percolam, guardando uma estreita relação com os tipos de rochas drenadas e com os produtos das atividades humanas adquiridos ao longo de seu trajeto. Comumente, quando da exploração de águas subterrâneas, o interesse volta-se para a quantidade de água; a composição química e a qualidade correlata aparecem em plano secundário, não sendo cotejadas a qualidade atual com os usos a que se destinam as águas exploradas, nem eventuais conflitos de uso. O aumento das demandas de água no meio rural tem levado a um maior número de perfurações de poços tubulares em geral.

Esta é a situação, por exemplo, da região ao longo do rio TaquariAntas, a qual vem sendo habitada por colonização informal. A água retirada através de poços tubulares (raras vezes de fontes) é usada para muitas finalidades, tais como consumo próprio, irrigação e dessedentação de animais. Na área selecionada para este estudo, no curso inferior do rio das Antas, serão implantadas três usinas hidrelétricas cujas cotas máximas dos reservatórios atingirão 111,5 m (UHE 14 de Julho), 157,37 m (UHE Monte Claro) e 246,6 m (UHE Castro Alves). Os estudos hidrogeólogicos em locais onde serão instalados reservatórios hidrelétricos no Brasil intensificaram-se na década de $90^{1-4}$, tendo em vista as possíveis interferências qualitativas e quantitativas nos aquíferos decorrentes da implantação/operação de hidrelétricas.

No caso de haver contaminantes dissolvidos na água subterrânea o transporte destes, de um aqüífero a um rio, toma lugar através da interface água subterrânea/água de superfície onde os processos são governados pela rápida mudança nas condições físicas e químicas ${ }^{5}$. O objetivo da presente pesquisa é caracterizar a qualidade das águas subterrâneas na área de influência dos futuros barramentos localizados na bacia do rio Taquari-Antas antes da

*e-mail: gerpro.pesquisa@fepam.rs.gov.br construção das barragens. As informações técnicas irão servir para auxiliar no uso racional dos recursos hídricos subterrâneos para o abastecimento das comunidades rurais, que não são servidas por águas superficiais e, também, ser um estado de referência destes antes da construção dos reservatórios.

\section{LOCALIZAÇÃo DA ÁREA}

A região está inserida na bacia hidrográfica do rio TaquariAntas, entre as coordenadas UTM $6807000 \mathrm{mN}, 6776000 \mathrm{mN}$ e $433000 \mathrm{mE}, 476000 \mathrm{mE}$ (Figura 1). Três áreas de aproveitamento hidrelétrico da bacia, fazendo parte do Complexo Energético Rio

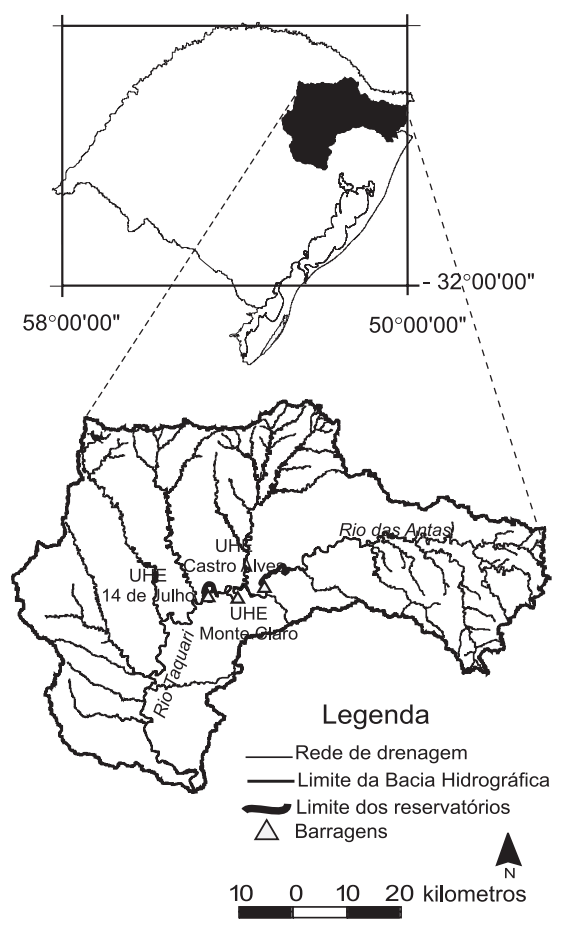

Figura 1. Mapa de localização da área estudada 
das Antas (CERAN), e que estão em diferentes fases de licenciamento ${ }^{6}$, foram selecionadas para o estudo: UHE $14 \mathrm{de} \mathrm{Ju}-$ lho, UHE Monte Claro e UHE Castro Alves. O conjunto está situado no curso inferior do rio das Antas: 14 de julho a $200 \mathrm{~km}$ da foz, Monte Claro a $238 \mathrm{~km}$ da foz e Castro Alves a $277 \mathrm{~km}$ da foz.

\section{GEOLOGIA E CARACTERIZAÇÃO DA ÁREA}

A geologia da área estudada consiste em um empilhamento de derrames vulcânicos, de idade Cretáceo Inferior, caracterizados por suítes bimodais básicas e ácidas, pertencentes à Bacia do Paraná. As rochas do tipo básica são predominantemente basaltos toleíticos $(\mathrm{ThB})$ e, em menor extensão, andesi-toleítos; as rochas ácidas, na parte superior da seqüência vulcânica, são representadas por riodacitos a riolitos ${ }^{7}$. Especificamente, a área de interesse está inserida nos derrames de rochas básicas comumente separados por camadas de pequena espessura de arenitos. Embora no Estado do Rio Grande do Sul, vários autores tenham estudado os basaltos da Bacia do Paraná ${ }^{8-10}$, na área selecionada para este estudo as pesquisas são raras. O conhecimento das relações estratigráficas e geoquímicas entre as seqüências de lava na região, bem como a espessura e extensão das seqüências individuais, é ainda fragmentário. Alguns autores ${ }^{7}$ definiram basaltos toleíticos e andesibasaltos em amostras localizadas em uma parte da área de estudo.

Exposições em cortes de estrada revelam que os derrames apresentam, geralmente, uma zona de topo e de base vesiculares ou amigdalóides, e uma zona central maciça (a mais espessa do derrame), com fraturamentos verticais e horizontais. Estes espaços são relacionados ao resfriamento do derrame e podem estar preenchidos por minerais secundários (quartzo, calcedônia, calcita, zeólitas e argilominerais). Solos ricos em argila que se formam por intemperismo entre as erupções, ou arenito, são localizadamente encontrados entre os derrames. Fraturas e falhas relacionadas a esforços tectônicos assumem maior importância na circulação das águas neste tipo de rocha ${ }^{11}$, pois provocam a integração de grande parte do pacote rochoso, formando zonas de infiltração e circulação de água e recarga das fraturas a partir da superfície do terreno.

Observações da geomorfologia revelam que há, na região, duas áreas com relevos distintos: nas imediações da UHE 14 de Julho ocorrem superfícies pouco acidentadas sem vales profundos, enquanto que na região das UHE's Monte Claro e Castro Alves observa-se um vale profundo, encaixado, com encostas íngremes e onde as efusivas ácidas, normalmente com altitudes próximas a $750 \mathrm{~m}$, capeiam as efusivas básicas.

Ao longo do trecho de interesse, o rio principal apresenta-se morfologicamente com meandros irregulares e, ocasionalmente, são encontradas ilhas e canais "trançados".

Sob o ponto de vista da organização sócio-econômica e espaci$\mathrm{al}^{12}$, a região estudada é homogênea, baseada em pequenas propriedades rurais e heranças culturais da população. A ocupação é caracterizada por loteamentos rurais de pequenas dimensões, destacando-se a agricultura e a pecuária. A agricultura na área de influência direta obedece às mesmas características apresentadas na área agrícola de influência indireta, sendo cultivado principalmente milho, uva, laranja, maçã, pêssego e bergamota. Na pecuária, ocorre a criação de gado leiteiro, suínos e, também, de aves.

\section{PARTE EXPERIMENTAL}

\section{Seleção dos poços para estudo}

Inicialmente, a fim de identificar os poços existentes na região, foi realizado um levantamento das informações preliminares através da coleta de dados junto a diversos órgãos/instituições de interesse: CORSAN/SUHIDRO; Programa de açudes e poços/PAP - Departamento de Assuntos do Interior/DEFIN - Secretaria de Obras Públicas e Saneamento/SOPS; Companhia de Pesquisas e Recursos Minerais/CPRM e Divisão de Vigilância Sanitária - DVS. Junto à FEPAM, foi obtido o trabalho "Avaliação quali-quantitativa dos recursos hídricos da Bacia Taquari-Antas"13 e o relatório para obtenção da licença prévia ${ }^{\circ}$ 0696/2001 - DL apresentado à Fundação Estadual de Proteção Ambiental - FEPAM pela Companhia Energética Rio das Antas ${ }^{14}$.

$\mathrm{Na}$ seqüência, foi efetuada uma investigação de campo para confirmação das informações, utilizando-se como base cartográfica as cartas topográficas na escala 1:50.000 da Diretoria do Serviço Geográfico do Ministério do Exército (DSG) e um GPS ("Global System Position") da marca Trimble (com margem de erro de $10 \mathrm{~m}$ ). Na confecção do mapa de localização dos poços foram utilizados softwares para digitalização (AUTOCAD) e interpolação de dados (SURFER). O mapeamento do conjunto de fraturas foi elaborado a partir da foto-interpretação de fotografias aéreas na escala 1:60.000 (Projeto AST10, 1964/1965 realizado pelo Exército Brasileiro, 1 ${ }^{\mathrm{a}}$ DL). Os diversos dados obtidos foram cruzados no Sistema de Informação Geográfica ArcView (GIS) 3.2. windows.

A partir dessas informações, foram selecionados sete poços para proceder ao monitoramento qualitativo das águas subterrâneas. A amostragem foi efetuada no período entre novembro de 2002 e março de 2003, em campanhas bimestrais, e seguiu os procedimentos constantes da NBR $9898^{15}$.

\section{Coleta das amostras e medições dos parâmetros físicos e químicos}

As amostras de águas subterrâneas foram coletadas a partir de poços domésticos, usando o sistema de bombeamento instalado no próprio poço. Este tipo de poço está em uso constante e, por este motivo, não houve a necessidade de bombeamento prolongado prévio. Os métodos de amostragem e preservação de águas seguiram os procedimentos adotados pelo Standard Methods ${ }^{16}$ e NBR $9898^{15}$.

Foram estipulados $20 \mathrm{~min}$ de bombeamento para assegurar a coleta de água a partir de amostras de água não estagnada. Sempre que possível, foram efetuadas leituras dos níveis estático e dinâmico com um medidor de nível eletrônico do tipo fita elétrica.

Os parâmetros temperatura $(\mathrm{T}), \mathrm{pH}$, sólidos totais dissolvidos (STD), salinidade e condutividade foram medidos in loco.

\section{Procedimento de laboratório}

Para a determinação dos metais dissolvidos, a amostra era filtrada em membrana de éster celulose de porosidade $0,45 \mu \mathrm{m}^{16}$. Nesta porosidade ainda são encontradas no filtrado partículas de tamanho coloidal (diâmetro entre 0,01 e $1 \mu \mathrm{m}$ ) e, portanto, não pode ser considerada, na realidade, a fração totalmente dissolvida ${ }^{17-19}$. Posteriormente à filtração, as amostras foram preservadas com $\mathrm{HNO}_{3}$ suprapuro e com clorofórmio para metais e íons maiores, respectivamente, e estocadas a $4{ }^{\circ} \mathrm{C}^{16}$.

As análises foram realizadas em duplicatas, para a determinação de todos os parâmetros estudados.

A determinação dos íons metálicos $\mathrm{Al}, \mathrm{Cd}, \mathrm{Pb}, \mathrm{Co}, \mathrm{Cu}, \mathrm{Cr}, \mathrm{Fe}$, Mn, Ni e Zn foi feita por Espectrometria de Absorção Atômica com Chama no Forno de Grafite e pela técnica da geração de hidretos.

A determinação dos íons maiores $\left(\mathrm{Ca}^{2+}, \mathrm{Mg}^{2+}, \mathrm{Na}^{+}, \mathrm{K}^{+}, \mathrm{NH}_{4}^{+}\right.$, $\mathrm{SO}_{4}^{2-}, \mathrm{NO}_{3}^{-}, \mathrm{Cl}^{-}$e $\mathrm{F}^{-}$) foi feita por Cromatografia Iônica, utilizando equipamento Dionex modelo DX 500 com detector de condutividade elétrica. 
A alcalinidade (referida como $\mathrm{CaCO}_{3}$ ) foi determinada pelo método potenciométrico $2320^{16}$, através da titulação com $\mathrm{HCl} 0,02 \mathrm{~N}$.

A investigação do material em suspensão para determinar sua origem e relação com a composição da água subterrânea foi realizada através da análise por microscópio eletrônico de varredura (MEV). Foram filtrados $150 \mathrm{ml}$ de água, para cada poço selecionado no estudo, com filtros Millipore, de membrana de éster de celulose (poro $0,45 \mu \mathrm{m}$, diâmetro $47 \mathrm{~mm}$ ). Os filtros foram levados à estufa em temperatura de $30{ }^{\circ} \mathrm{C}$, até atingirem peso constante para retirada da água das amostras e posterior metalização. Esta temperatura foi selecionada pelo fato de que se houver argilominerais nas amostras, os mesmos deverão ser preservados para haver uma identificação fiel do material que se encontra no filtro. Tratamentos de aquecimento em materiais argilosos podem ocasionar transformações ou decomposições dos mesmos. Em sistema aberto (as moléculas escapam ou são puxadas por um fluxo de gás neutro), a água molecular fracamente fixada sobre as superfícies externas e internas das partículas de argila evaporam-se a $56,8{ }^{\circ} \mathrm{C}{ }^{20}$.

Seções de filtros foram fixadas em "stabs" do MEV com fita de algodão dupla face e revestidas com ouro antes das micro-análises e de serem fotografadas. $\mathrm{O}$ aparelho utilizado é equipado com detector de elétrons e espectrômetro de energia dispersiva (EDS, "energy dispersive spectrometer"). A tensão de feixe utilizada foi de $25 \mathrm{kV}$, a abertura de $20 \mu \mathrm{m}$ e um tempo de aquisição para os espectros de EDS de $100 \mathrm{~s}$. A observação da concentração de partículas foi obtida através de fotografias feitas no MEV com a varredura em seções de cada filtro, com ampliação X 180 (aquela que melhor se adequou a todas as membranas, em função do tamanho do material depositado sobre elas).

\section{Tratamento dos dados}

Foi aplicada a análise estatística aos dados obtidos no estudo de qualidade da água usando o software SPSS versão 9.0 através dos seguintes métodos: Análise Estatística Descritiva, Análise de Variância (ANOVA). Quando os resultados das análises químicas se apresentavam abaixo dos limites de detecção da técnica utilizada, foram considerados como a metade dos limites de detecção nas propostas das análises estatísticas ${ }^{21}$. Esse procedimento é normal em análise estatística na área de imputação dos dados, para não ficarem lacunas no banco de dados. Foram considerados os sete poços, as três campanhas e quinze variáveis selecionadas. Foram selecionadas todas as variáveis para a aplicação dos métodos estatísticos.

O cálculo do balanço iônico ${ }^{22}$ foi aplicado nas sete amostras estudadas para averiguar o controle de qualidade das análises. A equação do balanço de carga iônica é definida como:

Erro da reação $=\frac{\Sigma \text { cátions }-\Sigma \text { ânions }}{\Sigma \text { (cátions }+ \text { ânions })} \times 100$

Nessa equação, são usadas concentrações em meq/L de cátions e ânions.

\section{RESULTADOS E DISCUSSÃO}

Características dos poços tubulares e qualidade das águas subterrâneas

A Tabela 1 e a Figura 2 mostram a localização e a descrição dos poços de captação. Foram cadastrados trinta e três poços tubulares profundos que estão em uso. Os poços apresentam profundidade média de 101,87 m, variando entre 29 e 206 m; 54,55\% dos poços apresentam profundidades inferiores a $102 \mathrm{~m}$. Esses poços são particulares, que abastecem a uma só família ou comunitários, que abastecem até 56 famílias. A água é utilizada para uso doméstico, irrigação e dessedentação de animais.

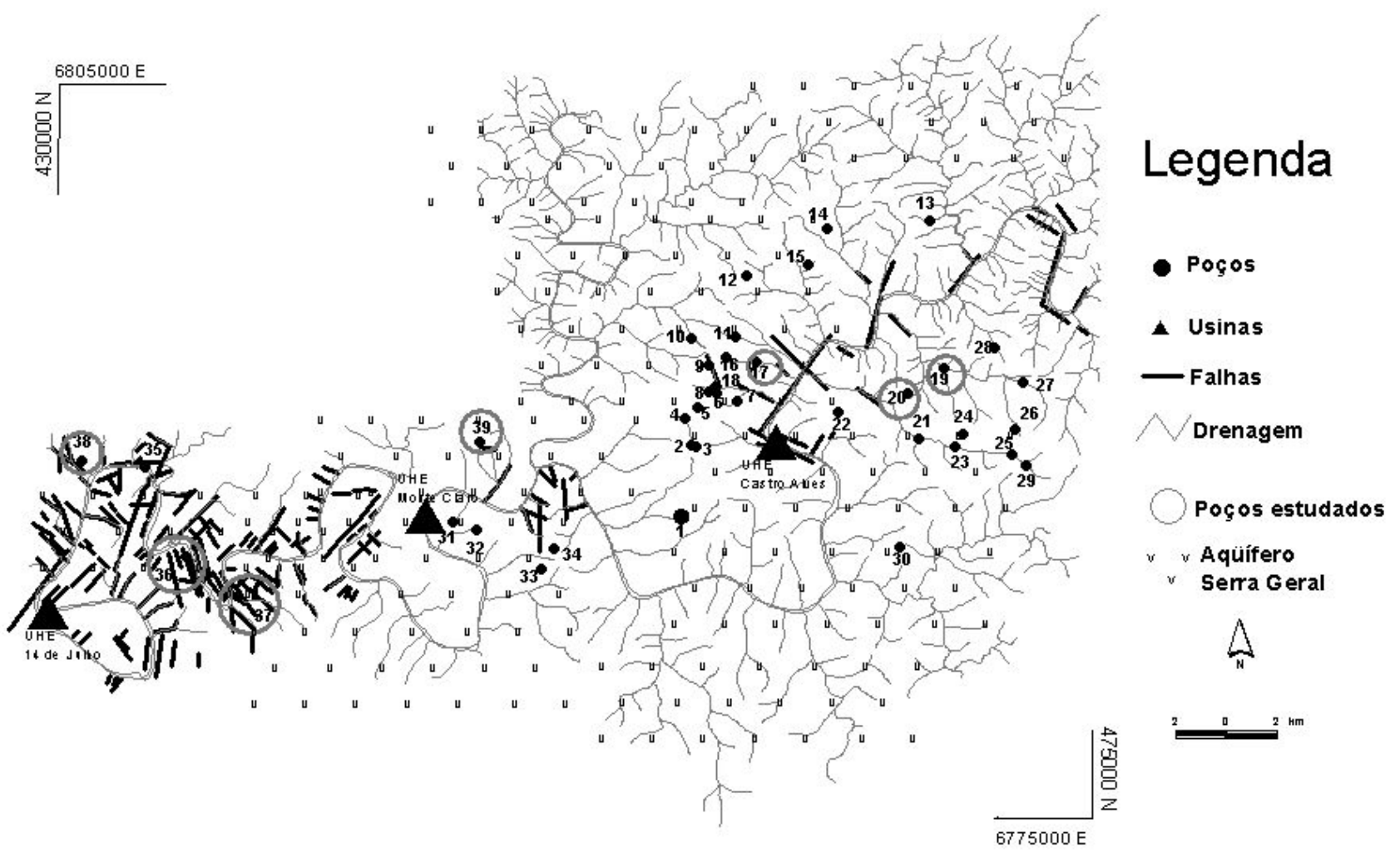

Figura 2. Mapa hidrogeológico simplificado da área estudada 
Tabela 1. Cadastro dos poços tubulares na área de influência dos futuros reservatórios hidrelétricos

\begin{tabular}{|c|c|c|c|c|c|c|c|}
\hline Poço & Município & Localidade & Tipo & Coordenadas & Altitude & Profundidade & $\mathrm{N}^{\circ}$ de famílias \\
\hline 1 & Nova Roma do Sul & Fagundes Varela & comunitário & $\begin{array}{c}459683 \\
6788524\end{array}$ & $642 \mathrm{~m}$ & $100 \mathrm{~m}$ & 60 \\
\hline 2 & Nova Roma do Sul & Fagundes Varela & comunitário & $\begin{array}{c}459707 \\
6790889\end{array}$ & $642 \mathrm{~m}$ & $148 \mathrm{~m}$ & 12 \\
\hline 3 & Nova Roma do Sul & Fagundes Varela & comunitário & $\begin{array}{c}459937 \\
6790810\end{array}$ & $649 \mathrm{~m}$ & $65 \mathrm{~m}$ & 18 \\
\hline 4 & Nova Roma do Sul & Traves Carlos Leopoldo & comunitário & $\begin{array}{l}459485 \\
6791947\end{array}$ & $598 \mathrm{~m}$ & $62 \mathrm{~m}$ & 39 \\
\hline 5 & Nova Roma do Sul & Traves Carlos Leopoldo & comunitário & $\begin{array}{l}460000 \\
6792374\end{array}$ & $630 \mathrm{~m}$ & $95 \mathrm{~m}$ & - \\
\hline 10 & Nova Roma do Sul & Linha Paranaguá Oeste & comunitário & $\begin{array}{l}459745 \\
6795110\end{array}$ & $635 \mathrm{~m}$ & $80 \mathrm{~m}$ & 28 \\
\hline 11 & Nova Roma do Sul & Vila Paranaguá Leste & comunitário & $\begin{array}{l}461427 \\
6795177\end{array}$ & $606 \mathrm{~m}$ & $84 \mathrm{~m}$ & 45 \\
\hline 12 & Nova Roma do Sul & Nova Treviso & comunitário & $\begin{array}{l}461900 \\
6797583\end{array}$ & $670 \mathrm{~m}$ & $37 \mathrm{~m}$ & 45 \\
\hline 13 & Nova Roma do Sul & Linha Trajano & - & $\begin{array}{l}460040 \\
6799746\end{array}$ & $647 \mathrm{~m}$ & $29 \mathrm{~m}$ & - \\
\hline 14 & Nova Roma do Sul & Linha Trajano & - & $\begin{array}{c}465002 \\
6799390\end{array}$ & $638 \mathrm{~m}$ & $100 \mathrm{~m}$ & - \\
\hline 15 & Nova Roma do Sul & Linha São Paulo & comunitário & $\begin{array}{c}464306 \\
6797998\end{array}$ & $613 \mathrm{~m}$ & $72 \mathrm{~m}$ & 11 \\
\hline 16 & Nova Roma do Sul & São Vicente & comunitário & $\begin{array}{c}461097 \\
6794328\end{array}$ & $674 \mathrm{~m}$ & $120 \mathrm{~m}$ & 40 \\
\hline 17 & Nova Roma do Sul & São Vicente & particular & $\begin{array}{c}462228 \\
6794143\end{array}$ & $577 \mathrm{~m}$ & $90 \mathrm{~m}$ & 1 \\
\hline 18 & Nova Roma do Sul & Poço Gladimir Faver & particular & $\begin{array}{l}460425 \\
6792995\end{array}$ & $580 \mathrm{~m}$ & $122 \mathrm{~m}$ & 1 \\
\hline 19 & Nova Pádua & Cerro Grande & particular & $\begin{array}{r}469561 \\
6793893\end{array}$ & $472 \mathrm{~m}$ & $126 \mathrm{~m}$ & 1 \\
\hline 20 & Nova Pádua & Soc.de abast. água d'barra & comunitário & $\begin{array}{c}468197 \\
6792936\end{array}$ & $574 \mathrm{~m}$ & $206 \mathrm{~m}$ & 31 \\
\hline 21 & Nova Pádua & Travessão Mutzel & comunitário & $\begin{array}{l}468603 \\
6791142\end{array}$ & $592 \mathrm{~m}$ & $206 \mathrm{~m}$ & 31 \\
\hline 22 & Nova Pádua & Travessão Leonel & comunitário & $\begin{array}{c}465457 \\
6792181\end{array}$ & $647 \mathrm{~m}$ & $104 \mathrm{~m}$ & 25 \\
\hline 23 & Nova Pádua & Travessão Bonito & comunitário & $\begin{array}{c}470036 \\
6790845\end{array}$ & $612 \mathrm{~m}$ & $154 \mathrm{~m}$ & 28 \\
\hline 24 & Nova Pádua & Travessão Bonito & comunitário & $\begin{array}{r}470313 \\
6791303\end{array}$ & $700 \mathrm{~m}$ & $162 \mathrm{~m}$ & 6 \\
\hline 25 & Nova Pádua & Travessão Paredes & comunitário & $\begin{array}{c}472232 \\
6790539\end{array}$ & $697 \mathrm{~m}$ & $46 \mathrm{~m}$ & 6 \\
\hline 27 & Nova Pádua & Santo Isidoro & comunitário & $\begin{array}{l}472705 \\
6793373\end{array}$ & $639 \mathrm{~m}$ & $91 \mathrm{~m}$ & 20 \\
\hline 28 & Nova Pádua & Aciolli/Cerro Largo & comunitário & $\begin{aligned} 471595 \\
6794738\end{aligned}$ & $628 \mathrm{~m}$ & $110 \mathrm{~m}$ & 22 \\
\hline 29 & Nova Pádua & São João Bosco/divisa & comunitário & $\begin{array}{c}472797 \\
6790093\end{array}$ & $735 \mathrm{~m}$ & $143 \mathrm{~m}$ & 42 \\
\hline 30 & Nova Pádua & Curuzu & comunitário & $\begin{array}{c}467857 \\
6786918\end{array}$ & $677 \mathrm{~m}$ & $136 \mathrm{~m}$ & 56 \\
\hline 31 & Pinto Bandeira & $5^{\circ}$ alta & particular & $\begin{array}{c}450401 \\
6787856\end{array}$ & $572 \mathrm{~m}$ & $116 \mathrm{~m}$ & 1 \\
\hline 32 & Pinto Bandeira & $5^{\circ}$ alta & particular & $\begin{array}{l}451310 \\
6787562\end{array}$ & $593 \mathrm{~m}$ & $70 \mathrm{~m}$ & 1 \\
\hline 33 & Pinto Bandeira & Ciro Arcari & particular & $\begin{array}{c}453867 \\
6786020\end{array}$ & $593 \mathrm{~m}$ & $56 \mathrm{~m}$ & 1 \\
\hline 34 & Pinto Bandeira & Linha Brasil & particular & $\begin{array}{c}454348 \\
6786851\end{array}$ & $625 \mathrm{~m}$ & $65 \mathrm{~m}$ & 1 \\
\hline 36 & Bento Gonçalves & Distrito de Tuiuti & particular & $\begin{array}{c}440012 \\
6786502\end{array}$ & $145 \mathrm{~m}$ & $120 \mathrm{~m}$ & 1 \\
\hline 37 & Bento Gonçalves & Distrito de Tuiuti & comunitário & $\begin{array}{c}442045 \\
6784973\end{array}$ & $140 \mathrm{~m}$ & $54 \mathrm{~m}$ & 32 \\
\hline 38 & Cotiporã & $\begin{array}{l}\text { Capela Sagrado Coração } \\
\text { de Jesus }\end{array}$ & particular & $\begin{array}{c}435913 \\
6790275\end{array}$ & $129 \mathrm{~m}$ & $120 \mathrm{~m}$ & 1 \\
\hline 39 & Bento Gonçalves & Linha Barros Cassal & comunitário & $\begin{array}{c}451485 \\
67891020\end{array}$ & $590 \mathrm{~m}$ & $147 \mathrm{~m}$ & 2 \\
\hline
\end{tabular}


A estrutura do poço acima da superfície do terreno é formada por uma tubulação que sobressai do nível do solo em torno de 20 $\mathrm{cm}$. Capeando o solo ou a rocha não consolidada, há uma placa de concreto que serve para proteger o poço de contaminações. Os poços possuem um sistema de bombeamento composto por um motor elétrico e uma bomba, localizados abaixo da superfície do solo. Quando o sistema é acionado, a água é lançada até um reservatório ou caixa d'água, para então ser distribuída aos consumidores.

As amostragens de água foram realizadas em determinados poços (números 17, 19, 20, 36, 37, 38 e 39) (Figura 2), cuja escolha foi feita em função, principalmente, da proximidade com as cotas dos futuros reservatórios, a presença de fraturas e da localização na zona de influência indireta das futuras usinas ${ }^{12}$. A partir da Figura 2 observa-se que não houve uma distribuição uniforme da captação de água através de poços tubulares na região, o que pode ser atribuído a não existência de moradias nas encostas das regiões mais íngremes (na área da UHE Castro Alves).

A Tabela 2 mostra os resultados das análises dos parâmetros físicos e químicos das águas coletadas nos sete poços estudados. Foram observadas condições relativamente estáveis de temperatura e de $\mathrm{pH}$, sem variações significativas nas diferentes campanhas de amostragens. $\mathrm{O} \mathrm{pH}$, nos diferentes poços, variou entre 6,2 e 8,5, indicando valores próximos a neutro até levemente alcalinos.

As águas analisadas apresentaram como característica principal a fraca mineralização, com valores de Sólidos Totais Dissolvidos (STD) variando de 50 a $170 \mathrm{mg} / \mathrm{L}$, inserindo-se nos padrões aceitos para a água potável ${ }^{23}$. Todos os valores encontrados para sólidos totais dissolvidos apresentaram-se bem inferiores a 1000 $\mathrm{mg} / \mathrm{L}$, enquadrando-se também nos valores admissíveis para águas potáveis $^{23}$. Embora sejam fracamente mineralizadas as águas, segundo os íons dominantes, são em sua maioria bicarbonatadas.

Os poços com valores mais elevados de condutividade elétrica $(17,37$ e 38$)$ corresponderam àqueles com maiores concentrações de $\mathrm{HCO}_{3}^{-}$, acima de $100 \mathrm{mg} / \mathrm{L}$ (Tabela 2).

A Tabela 3 mostra a composição química quanto aos íons maiores das amostras para as três campanhas estudadas. Bicarbonato é o principal ânion destas águas, com concentrações variando entre 46,1 e 156,2 mg/L; outros ânions maiores, como sulfato e cloreto, comumente apresentaram quantidades menores que $6 \mathrm{mg} / \mathrm{L}$. A razão molar entre $\mathrm{HCO}_{3}^{-}$e $\mathrm{Ca}^{2+}$ nas águas bicarbonatadas cálcicas foi próxima a 3:1.

As análises químicas das águas locadas no diagrama de Piper $^{21}$ revelaram uma variação espacial nos parâmetros químicos, formando um grupo com a maioria dos poços; somente um poço não pertence à fácies dominante (Figura 3) Observa-se uma dispersão dos parâmetros que formam o grupo, indicando uma variação somente na concentração do somatório de íons $\mathrm{Na}+\mathrm{K}$ com valores que vão de 7,063 a 13,1 mg/L. Neste grupo os íons predominantes são cálcio e bicarbonato, classificando as águas como do tipo bicarbo-

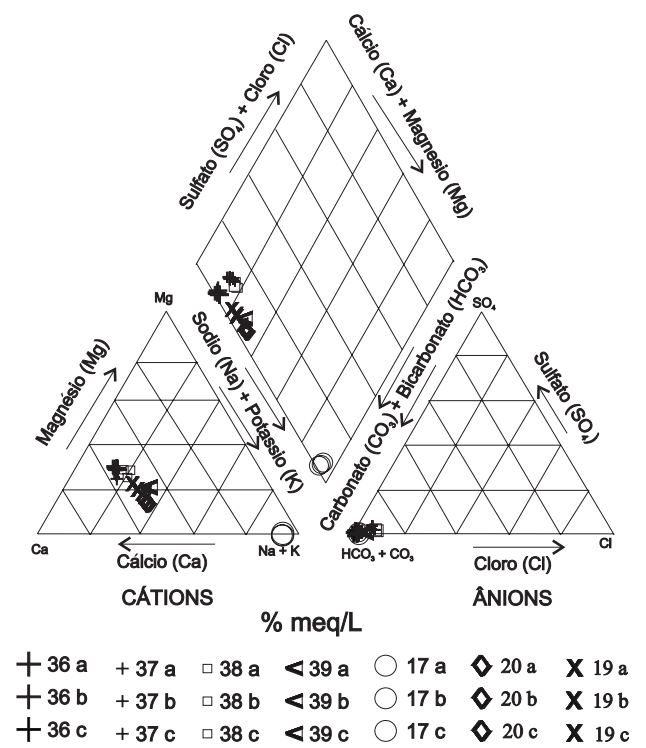

Figura 3. Diagrama de Piper com os dados dos íons maiores para as amostras das águas subterrâneas na área estudada

Tabela 2. Parâmetros físico - químicos para as amostras de águas subterrâneas, determinados nas três campanhas de amostragem

\begin{tabular}{|c|c|c|c|c|c|}
\hline poço/campanha & Tágua $\left({ }^{\circ} \mathrm{C}\right)$ & $\mathrm{pH}$ & Condutividade $(\mathrm{mS} / \mathrm{cm})$ & Salinidade & $\mathrm{STD}(\mathrm{mg} / \mathrm{L})$ \\
\hline Poço 36a & 21,5 & 6,80 & 179 & n.d. & 89,0 \\
\hline Poço 36b & 20,0 & 6,80 & 175 & n.d. & 88,0 \\
\hline Poço 36c & 20,0 & 6,80 & 174 & n.d. & 78,0 \\
\hline Poço 37a & 22,0 & 7,20 & 332 & n.d. & 166 \\
\hline Poço 37b & 22,0 & 7,20 & 336 & n.d. & 170 \\
\hline Poço 37c & 22,4 & 7,00 & 332 & n.d. & 150 \\
\hline Poço 38a & 22,0 & 6,90 & 228 & n.d. & 114 \\
\hline Poço $38 b$ & 21,0 & 6,80 & 240 & n.d. & 120 \\
\hline Poço 38c & 22,6 & 6,80 & 217 & n.d. & 98,0 \\
\hline Poço 39a & 19,0 & 6,20 & 106 & n.d. & 53,0 \\
\hline Poço 39b & 19,0 & 6,30 & 104 & n.d. & 53,0 \\
\hline Poço 39c & 18,5 & 6,60 & 110 & n.d. & 50,0 \\
\hline Poço 17a & 19,0 & 8,50 & 203 & n.d. & 101 \\
\hline Poço 17b & 19,0 & 8,50 & 203 & n.d. & 99,0 \\
\hline Poço $17 \mathrm{c}$ & 20,3 & 8,00 & 207 & n.d. & 96,0 \\
\hline Poço 20a & 19,0 & 6,30 & 133 & n.d. & 66,0 \\
\hline Poço $20 \mathrm{~b}$ & 19,0 & 6,70 & 137 & n.d. & 68,5 \\
\hline Poço 20c & 20,0 & 6,70 & 150 & n.d. & 68,0 \\
\hline Poço 19a & 20,0 & 7,50 & 168 & n.d. & 84,0 \\
\hline Poço 19b & 20,0 & 7,40 & 169 & n.d. & 84,9 \\
\hline Poço 19c & 20,0 & 7,30 & 198 & n.d. & 69,0 \\
\hline
\end{tabular}

a: $1^{\text {a }}$ campanha; b: 2a campanha, c: $3^{\text {a }}$ campanha; STD - Sólidos totais dissolvidos; n.d.- Não detectado 
Tabela 3, Parâmetros químicos (mg/L) para as amostras de águas subterrâneas nas três campanhas de amostragem

\begin{tabular}{|c|c|c|c|c|c|c|c|c|c|c|c|c|}
\hline poço & $\begin{array}{c}\text { Alcalinidade } \\
\text { total } \mathrm{mg} \mathrm{CaCO}_{3} / \mathrm{L}\end{array}$ & $\mathrm{Na}$ & $\mathrm{K}$ & $\mathrm{Ca}$ & $\mathrm{Mg}$ & $\mathrm{Cl}$ & $\mathrm{HCO}_{3}$ & $\mathrm{CO}_{3}$ & $\mathrm{SO}_{4}$ & $\mathrm{~F}$ & $\mathrm{NO}_{3}$ & $\mathrm{NH}_{4}$ \\
\hline $36 a$ & & 7,20 & 0,0720 & 19,6 & 6,83 & 1,18 & 87,7 & & 2,13 & 0,0820 & 0,560 & 0,433 \\
\hline $36 b$ & & 7,00 & 0,0610 & 19,1 & 6,63 & 1,21 & 87,8 & & 1,98 & 0,0640 & 2,93 & \\
\hline $36 \mathrm{c}$ & $87,900 *$ & 7,30 & 0,0680 & 19,4 & 6,56 & 1,18 & 87,7 & & 1,98 & 0,0600 & 2,54 & \\
\hline $37 \mathrm{a}$ & & 13,1 & 0,190 & 39,2 & 10,0 & 5,60 & 156 & & 5,70 & 0,108 & 3,02 & \\
\hline $37 \mathrm{~b}$ & & 13,0 & 0,200 & 39,1 & 10,4 & 5,10 & 156 & & 5,40 & 0,139 & 14,3 & \\
\hline $37 \mathrm{c}$ & $122,90 *$ & 13,0 & 0,200 & 39,8 & 10,8 & 5,73 & 156 & & 5,04 & 0,121 & 14,4 & \\
\hline $38 \mathrm{a}$ & & 11,0 & 0,350 & 24,8 & 7,40 & 4,70 & 104 & & 2,80 & 0,183 & 2,40 & \\
\hline $38 b$ & & 9,42 & 0,410 & 24,0 & 7,53 & 5,04 & 105 & & 2,60 & 0,180 & 10,9 & \\
\hline $38 \mathrm{c}$ & $104,40 *$ & 11,0 & 0,370 & 24,9 & 7,93 & 4,70 & 104 & & 2,70 & 0,164 & 11,0 & \\
\hline $39 a$ & & 7,31 & 1,04 & 10,1 & 2,63 & 1,03 & 46,1 & & 0,710 & 0,210 & 1,30 & \\
\hline $39 b$ & & 7,04 & 1,10 & 10,8 & 2,62 & 1,20 & 45,8 & & 0,760 & 0,184 & 5,97 & \\
\hline $39 \mathrm{c}$ & $46,000 *$ & 7,30 & 1,20 & 10,7 & 2,70 & 1,11 & 46,1 & & 0,733 & 0,183 & 6,02 & \\
\hline $17 \mathrm{a}$ & & 50,1 & 0,120 & 3,31 & 0,0280 & 0,950 & 101 & 2,31 & 2,04 & 0,904 & 0,680 & \\
\hline $17 \mathrm{~b}$ & & 49,2 & 1,00 & 3,34 & 0,0320 & 1,05 & 101 & 2,52 & 1,01 & 0,900 & 3,10 & \\
\hline $17 \mathrm{c}$ & $103,40 *$ & 49,0 & 0,0750 & 3,43 & 0,0390 & 1,04 & 101 & 2,55 & 0,990 & 0,820 & 3,22 & \\
\hline $20 \mathrm{a}$ & & 11,4 & 1,02 & 16,2 & 2,50 & 1,10 & 65,2 & & 0,630 & 0,150 & 1,40 & \\
\hline $20 \mathrm{~b}$ & & 11,0 & 1,10 & 15,5 & 2,50 & 1,20 & 65,2 & & 0,660 & 0,150 & 6,40 & \\
\hline $20 \mathrm{c}$ & $65,000 *$ & 9,60 & 1,02 & 14,4 & 2,50 & 1,20 & 64,5 & & 0,680 & 0,130 & 6,22 & \\
\hline $19 \mathrm{a}$ & & 11,1 & 0,420 & 19,7 & 4,61 & 0,900 & 84,6 & & 1,12 & 0,270 & 0,720 & \\
\hline $19 \mathrm{~b}$ & & 11,0 & 0,410 & 19,5 & 4,70 & 1,40 & 82,7 & & 1,12 & 0,240 & 4,35 & \\
\hline $19 \mathrm{c}$ & $83,400 *$ & 8,71 & 0,310 & 16,6 & 4,21 & 1,03 & 82,8 & & 1,14 & 0,264 & 3,70 & \\
\hline LD & & 0,0000500 & 0,0000900 & 0,000130 & 0,0000710 & 0,00144 & & & 0,00570 & 2,82 & 0,00470 & 0,0620 \\
\hline
\end{tabular}

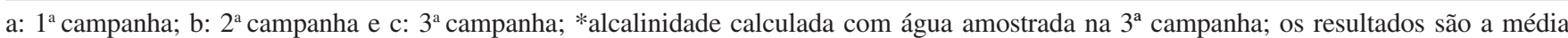
de 3 determinações feitas para cada poço; $\mathrm{LD}=$ limite de detecção

natadas cálcicas $\left(\mathrm{Ca}-\mathrm{HCO}_{3}\right)$; as concentrações de cálcio estão no intervalo entre 10,1 e $39,8 \mathrm{mg} / \mathrm{L}$.

No único poço que ficou em uma fácies separada (17) o cátion predominante foi o sódio, correspondendo a águas do tipo bicarbonatadas sódicas $\left(\mathrm{Na}-\mathrm{HCO}_{3}\right)$, com concentrações de íons $\mathrm{Na}+\mathrm{K}$ no intervalo entre 48,6 a $50,3 \mathrm{mg} / \mathrm{L}$, e concentração média $21,1 \mathrm{mg} / \mathrm{L}$. Este poço apresentou valores de $\mathrm{pH}$ e $\mathrm{Na}+\mathrm{K}$ mais altos em relação às demais amostras. A água, fortemente carente em cátions divalentes $\left(\mathrm{Ca}^{2+}\right.$ e $\left.\mathrm{Mg}^{2+}\right)$ e enriquecida em $\mathrm{Na}^{+}$sofreu, provavelmente, uma longa evolução geoquímica. A grande falta de cátions divalentes nesta água sugere não somente a presença de água antiga (água com maior tempo de residência) como também contribuições negligenciáveis de água moderna (água de recarga); ou, ainda, que estas águas percolaram áreas com rochas de composição química diferente, tais como intrusões alcalinas (o $\mathrm{Na}^{+}$poderia ser oriundo da nefelina) comuns de ocorrerem nos basaltos da Bacia do Paraná centro e norte, embora ainda não identificadas na Bacia do Paraná sul.

$\mathrm{O} \mathrm{Na}{ }^{+}$apresentou concentrações entre 7,00 e 50,1 mg/L, adequadas ao consumo humano ${ }^{23}$. Nas águas ricas em $\mathrm{Ca}^{2+} \mathrm{e}$ naquelas ricas em $\mathrm{Na}^{+}$, a concentração média de $\mathrm{Na}^{+}$foi 9,71 e 49,3 mg/L, respectivamente.

As concentrações de $\mathrm{HCO}_{3}^{-}, \mathrm{Ca}^{2+} \mathrm{e} \mathrm{Na}^{+}$podem resultar da dissolução dos feldspatos, especialmente plagioclásio cálcico, que são minerais que dissolvem facilmente, com redução do $\mathrm{CO}_{2}$ na água subterrânea. As seguintes equações são $\operatorname{propostas~}^{24}$ para a dissolução de feldspato sódico e cálcico (plagioclásio) :

feldspato cálcico:

$\mathrm{CaAl}_{2} \mathrm{Si}_{2} \mathrm{O}_{8}+2 \mathrm{CO}_{2}+3 \mathrm{H}_{2} \mathrm{O} \leftrightarrows \mathrm{Ca}^{2+}+2 \mathrm{HCO}_{3}^{-}+\mathrm{Al}_{2} \mathrm{Si}_{2} \mathrm{O}_{5}(\mathrm{OH})_{4}$ $s, c$, anortita $\quad g \quad l \quad a q \quad a q \quad s, c$, caolinita feldspato sódico:

$2 \mathrm{NaAlSi}_{3} \mathrm{O}_{8}+2 \mathrm{CO}_{2}+11 \mathrm{H}_{2} \mathrm{O} \leftrightarrows \mathrm{Na}^{+}+2 \mathrm{HCO}_{3}{ }^{-}+4 \mathrm{Si}(\mathrm{OH})_{4}+\mathrm{Al}_{2} \mathrm{Si}_{2} \mathrm{O}_{5}(\mathrm{OH})_{4}$ $s, c$, albita $\quad g \quad l \quad a q \quad a q \quad a q \quad s, c$, caolinita

$\mathrm{O} \mathrm{Ca}^{2+}$, embora em menores proporções, pode ser também proveniente da dissolução da calcita. Este mineral pode ocorrer, comumente, preenchendo vesículas e fissuras no basalto.

A dissolução da calcita pode ser um importante processo em um meio geológico pobre em carbonato. A água (na presença de $\mathrm{CO}_{2}$ atmosférico, contido na água da chuva ou proveniente da atividade orgânica dos solos) interage com carbonato de cálcio, produzindo $\mathrm{Ca}^{2+}$ e $\mathrm{HCO}_{3}^{-}$através da reação:

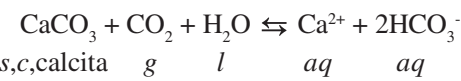

O conteúdo de magnésio variou entre 0,0318 e 10,8 mg/L. Águas ricas em cálcio apresentaram valores de magnésio entre 2,45 e $10,8 \mathrm{mg} / \mathrm{L}$, sendo que as concentrações mais elevadas estão associadas a águas com teores de cálcio mais altos (39,1 a 39,8 mg/L). Nas águas ricas em sódio, a porcentagem de $\mathrm{Mg}^{2+}$ mostrou-se consideravelmente reduzida $(0,0282$ a $0,0395 \mathrm{mg} / \mathrm{L})$.

Os cálculos da razão molar $\mathrm{Ca} / \mathrm{Mg}$ para as águas bicarbonatadas cálcicas mostraram no diagrama um espalhamento de dados e que os poços se agrupam com razões diferentes: nos poços 39 e 19 a razão é $2,5: 1$ e nos poços $20,36,37$ e 38 a razão é $2: 1$. O poço com água bicarbonatada sódica: 17 apresentou-se isolado, com razão $\mathrm{Ca}$ / Mg de aproximadamente 4:1.

$\mathrm{O} \mathrm{Mg}^{2+}$ parece ser oriundo da dissolução de minerais ferromagnesianos (piroxênios e olivinas) que ocorrem na rocha. A mudança nas concentrações de $\mathrm{Mg}^{2+}$ entre os poços poderia estar associada ao tempo de residência (tempo em que a água permaneceu em con- 
tato com a rocha) ou ao tempo decorrido desde a recarga (águas mais jovens ou mais velhas).

Os conteúdos de $\mathrm{SO}_{4}^{2-}$ foram variáveis e geralmente baixos, podendo resultar da dissolução de gipso, que é sulfato de cálcio hidratado $\left(\mathrm{CaSO}_{4} \cdot 2 \mathrm{H}_{2} \mathrm{O}\right)$. Todas as amostras têm conteúdos relativamente baixos de $\mathrm{K}^{+}$, que podem ser atribuídos à dissolução de feldspatos potássico, não muito abundante nos basaltos, ou de celadonita.

Concentrações de fluoreto entre 0,819 e $0,9049 \mathrm{mg} / \mathrm{L}$ foram determinadas para a água tipo bicarbonatada sódica e valores mais baixos, entre 0,0600 e 0,2649 $\mathrm{mg} / \mathrm{L}$, para águas bicarbonatadas cálcicas. Deste modo, apatita (na rocha) e fluorita (em fraturas) devem contribuir de maneira pouco significativa para os níveis de flúor na água. Devido à falta de uma fonte de íons cloreto no basalto, este íon não é comum em concentrações elevadas na água.

Como é conhecido, o nitrato é facilmente dissolvido nas águas subterrâneas e é muito móvel em fluxos subsuperficiais, difundindo-se muito rapidamente através de meio fraturado em subsuperfície. A concentração de nitrato aumentou a partir da $2^{\mathrm{a}}$ campanha (exceção para os poços 19, 20 e 36, onde a concentração de $\mathrm{NO}_{3}$ diminuiu na $3^{\mathrm{a}}$ campanha). As concentrações de nitrato nos poços 37 e 38 foram as mais elevadas, estando acima do valor máximo permitido para consumo humano que é de $10 \mathrm{mg} / \mathrm{L}^{23}$. Os nitratos ocorrem naturalmente nas águas por dissolução de rochas ou, principalmente, por oxidação bacteriana de matéria orgânica de origem predominantemente animal. As maiores concentrações de nitrato decorrem da utilização de fertilizantes e do lançamento de esgotos orgânicos. As concentrações elevadas encontradas no presente estudo podem ser decorrentes das atividades agropecuárias praticadas na região (agricultura e suinocultura).

A presença de íon amônio foi detectada somente na $1^{\mathrm{a}}$ campanha do poço $36(0,433 \mathrm{mg} / \mathrm{L})$, o que pode ter sido devido à presença de condições redutoras, em que a denitrificação de $\mathrm{NO}_{3}^{-}$por bactérias ocorreu, com produção de gás nitrogênio e íon amônio ${ }^{20}$. A ausência do íon amônio nas demais campanhas pode ser atribuída a condições oxidantes, em que as bactérias converteram $\mathrm{NH}_{4}^{+}$a íon nitrato.

O cálculo do balanço iônico mostrou que, para a maioria das amostras estudadas (21 amostras), os erros da reação estiveram dentro do intervalo de $10 \%$. As 4 amostras cujos erros estão entre 11 e $14 \%$ (Figura 4) representam valores atípicos e não interferem no resultado final das análises.

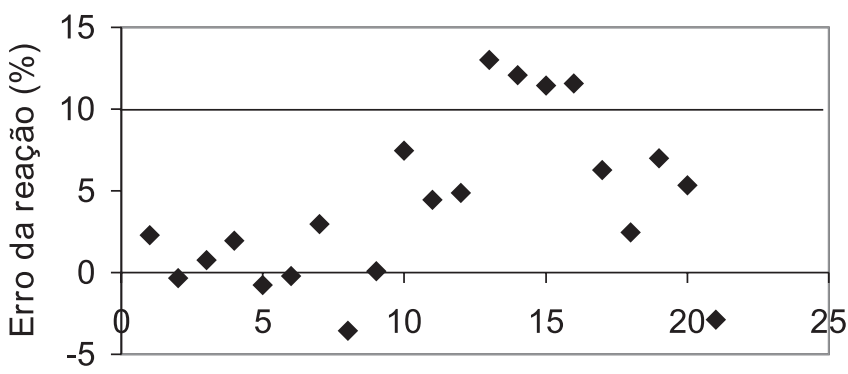

Número de amostras

Figura 4. Representação do erro da reação do balanço iônico (total de amostras $=21$ )

A correlação significativa entre o somatório de ânions e cátions mostra que um bom balanço iônico foi encontrado com $\mathrm{R}^{2}=0,9029$ (Figura 5).

As concentrações para a maioria dos íons metálicos analisados apresentam-se em níveis baixos (Tabela 4). Provavelmente, são pro-

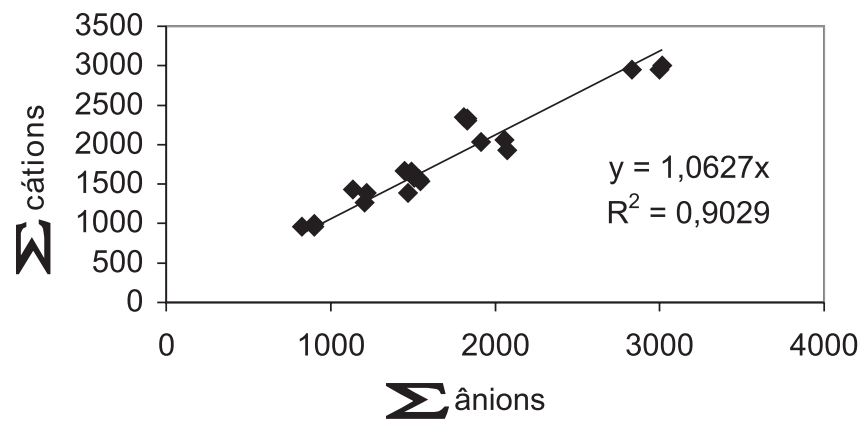

Figura 5. Correlação entre o somatório de ânions e cátions das análises das águas subterrâneas dos 7 poços (meq/L \%)

venientes da dissolução dos minerais. Dentre os íons metálicos, o $\mathrm{Al}^{3+}, \mathrm{Fet}, \mathrm{Mn}^{2+}$ e o $\mathrm{Zn}^{2+}$ são os que foram encontrados com maior freqüência nas campanhas de amostragens. $\mathrm{O} \mathrm{Al}^{3+}$, variou entre 0,0006 e $0,0040 \mathrm{mg} / \mathrm{L}$, e foi detectado apenas na $3^{\mathrm{a}}$ campanha. Este cátion é encontrado nos aluminossilicatos (plagioclásios) e piroxênios. O ferro, essencial para a nutrição humana, variou entre $0,0130 \mathrm{e}$ $0,4300 \mathrm{mg} / \mathrm{L}$, e foi detectado na $1^{\mathrm{a}}$ campanha somente nos poços 19 e 20. Este fato pode ser explicado pela pouca chuva que ocorreu no dia que antecedeu a coleta, implicando na precipitação do ferro. O ferro é comum nos óxidos de ferro (magnetita e ilmenita) e piroxênios. Este elemento excedeu o limite aceito para o consumo humano ${ }^{22} \mathrm{em}$ apenas uma amostra. $\mathrm{O} \mathrm{Mn}^{2+}$, que está intimamente associado com o ferro, é encontrado na estrutura dos piroxênios e variou entre 0,0001 e $0,0430 \mathrm{mg} / \mathrm{L}$. O $\mathrm{Zn}^{2+}$ foi o único detectado em praticamente todas as amostras, variando entre 0,0220 e 1,2700 mg/L. Este elemento é encontrado em piroxênios e em alguns fertilizantes. Este íon, como outros elementos metálicos de transição, é fortemente adsorvido pelas superfícies de óxidos hidratados, especialmente pelos óxidos de ferro e manganês. Em óxidos de ferro (comuns em basaltos e nas alterações de basaltos), a adsorção do zinco ${ }^{25}$ aumenta expressivamente com o aumento do $\mathrm{pH}$, desde próximo de zero de sorção em valores de $\mathrm{pH}$ fracamente ácidos (por ex. pH 5) à remoção essencialmente quantitativa da água em valores de $\mathrm{pH}$ maiores que 7,5 .

\section{Microscopia eletrônica}

Esta técnica permitiu visualizar os resíduos não filtráveis (material em suspensão), sua morfologia, granulometria; determinar sua composição elementar e visualizar a concentração de material nas membranas utilizadas na filtração da água.

A quantidade de resíduo não-filtrável variou entre 0,0024 (poço 39) e $0,0006 \mathrm{~g}$ (poço 37). Parece não haver relação entre a concentração de material e a profundidade do poço.

Análises semiquantitativas nos materiais retidos nos filtros indicam que os resíduos transportados na água subterrânea consistem principalmente de fases com $\mathrm{Si}, \mathrm{Al}, \mathrm{Na}, \mathrm{K}, \mathrm{Mg}, \mathrm{Fe}$, Ti e menores $\mathrm{P}, \mathrm{Cr}, \mathrm{Cl}, \mathrm{Cu}, \mathrm{Zn}$. O material é caracterizado por colóides $(0,45$ a $1 \mu \mathrm{m}$ ) ocorrendo principalmente isolados, como minerais xenomórficos, placas e ocasionalmente como esferas, e por partículas $(>1 \mu \mathrm{m})$, ocorrendo como agregados ou isoladas (com formas similares às dos colóides). Cristais de piroxênio que mantêm sua forma original e superfícies de dissolução de plagioclásio foram observados (Figura 6).

Microfotografias obtidas em aumento $180 \mathrm{X}$ indicaram que as membranas mostraram-se de heterogêneas (materiais em apenas uma área do filtro) a homogeneamente (materiais distribuídos por toda área do filtro) cobertas com resíduos não-filtráveis (um exemplo 
Tabela 4. Determinação de íons metálicos (mg/L) em amostras de águas subterrâneas

\begin{tabular}{|c|c|c|c|c|c|c|c|c|c|c|}
\hline poço & $\mathrm{Al}$ & $\mathrm{Cd}$ & $\mathrm{Pb}$ & Co & $\mathrm{Cu}$ & $\mathrm{Cr}$ & $\mathrm{Fe}$ & $\mathrm{Mn}$ & $\mathrm{Ni}$ & $\mathrm{Zn}$ \\
\hline $36 a$ & n.d. & n.d. & n.d. & n.d. & n.d. & n.d. & n.d. & n.d. & n.d. & 0,58 \\
\hline $36 b$ & n.d. & n.d. & n.d. & n.d. & n.d. & n.d. & 0.43 & n.d. & n.d. & 1,3 \\
\hline $36 \mathrm{c}$ & 0,0040 & n.d. & 0,0010 & n.d. & n.d. & 0,0010 & 0,019 & 0,00020 & n.d. & 0,55 \\
\hline $37 \mathrm{a}$ & n.d. & n.d. & n.d. & n.d. & n.d. & n.d. & n.d. & n.d. & n.d. & 0,022 \\
\hline $37 b$ & n.d. & n.d. & n.d. & n.d. & n.d. & n.d. & n.d. & n.d. & n.d. & 0,047 \\
\hline $37 \mathrm{c}$ & 0,00060 & n.d. & n.d. & n.d. & n.d. & n.d. & 0,021 & 0,00010 & n.d. & 0,77 \\
\hline $38 \mathrm{a}$ & n.d. & n.d. & n.d. & n.d. & n.d. & n.d. & n.d. & n.d. & n.d. & 0,77 \\
\hline $38 b$ & n.d. & n.d. & n.d. & n.d. & n.d. & n.d. & 0,030 & n.d. & n.d. & 0,89 \\
\hline $38 \mathrm{c}$ & 0,0020 & n.d. & n.d. & n.d. & n.d. & 0,00070 & 0,033 & 0,0090 & n.d. & 0,41 \\
\hline $39 a$ & n.d. & n.d. & n.d. & n.d. & n.d. & n.d. & n.d. & n.d. & n.d. & 0,59 \\
\hline $39 b$ & n.d. & n.d. & n.d. & n.d. & n.d. & n.d. & 0,024 & n.d. & n.d. & 0,77 \\
\hline $39 \mathrm{c}$ & 0,0010 & n.d. & n.d. & n.d. & n.d. & n.d. & 0,013 & 0,00030 & n.d. & n.d. \\
\hline $17 \mathrm{a}$ & n.d. & n.d. & n.d. & n.d. & n.d. & n.d. & n.d. & n.d. & n.d. & 0,030 \\
\hline $17 \mathrm{~b}$ & n.d. & n.d. & n.d. & n.d. & n.d. & n.d. & n.d. & n.d. & n.d. & 0,023 \\
\hline $17 \mathrm{c}$ & 0,0030 & n.d. & n.d. & n.d. & n.d. & n.d. & 0,025 & 0,00020 & n.d. & n.d. \\
\hline $20 \mathrm{a}$ & n.d. & n.d. & n.d. & n.d. & n.d. & n.d. & 0,030 & 0,013 & n.d. & 0,13 \\
\hline $20 \mathrm{~b}$ & n.d. & n.d. & n.d. & n.d. & n.d. & n.d. & 0,034 & 0,010 & n.d. & 0,15 \\
\hline $20 \mathrm{c}$ & 0,0010 & n.d. & 0,0010 & n.d. & n.d. & n.d. & 0,020 & 0,043 & n.d. & 0,15 \\
\hline $19 \mathrm{a}$ & n.d. & n.d. & n.d. & n.d. & n.d. & n.d. & 0,030 & n.d. & n.d. & 0,12 \\
\hline $19 b$ & n.d. & n.d. & n.d. & n.d. & n.d. & n.d. & 0,031 & n.d. & n.d. & 0,10 \\
\hline $19 \mathrm{c}$ & 0,0020 & n.d. & 0,00050 & n.d. & n.d. & n.d. & 0,021 & n.d. & n.d. & 0,14 \\
\hline LD & 0,00010 & 0,00010 & 0,00010 & 0,0050 & 0,010 & 0,00010 & 0,010 & 0,00010 & 0,0060 & 0,010 \\
\hline
\end{tabular}

n.d. = não detectado; $a=1^{a}$ campanha, $b=2^{a}$ campanha e $c=3^{a}$ campanha; $L D=$ limite de detecção
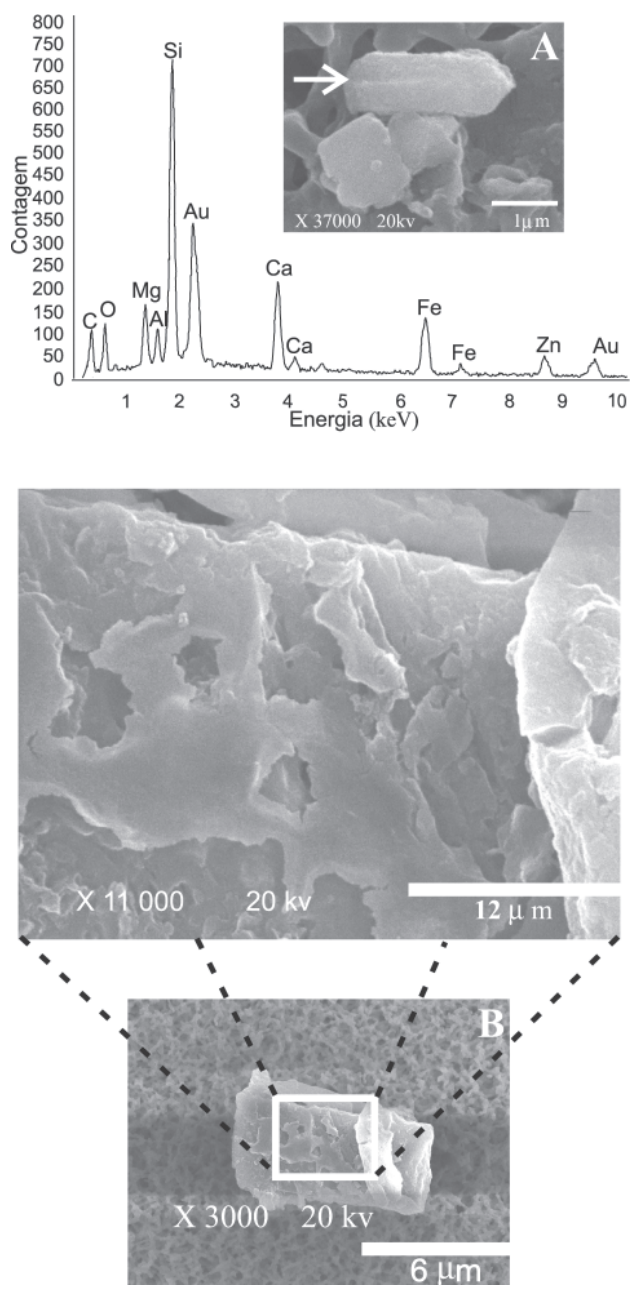

Figura 6. Minerais observados ao MEV em membranas de filtração. A: cristal de piroxênio com forma de cristalização monoclínica e B: cristal de plagioclásio mostrando superfície de dissolução típico é apresentado na Figura 7). O peso do material encontrado no filtro que está heterogeneamente coberto foi de 46,9283 g (poço 19) enquanto no filtro que está homogeneamente coberto por partículas a quantidade de resíduos é maior: 47,5119 g (poço 36).

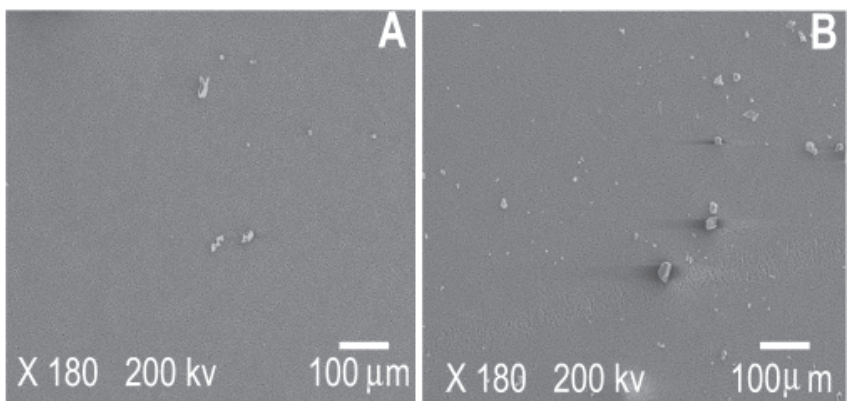

Figura 7. Microfotografias ao MEV de membranas de éster celulose por onde a água foi filtrada. A: heterogeneidade dos resíduos sobre o filtro (poço 19) e B: filtro com homogeneidade de resíduos (poço 36)

Os elementos detectados a partir de análises de EDS são os principais constituintes dos aluminossilicatos (feldspatos potássicos e plagioclásios), minerais ferromagnesianos (piroxênios) podendo ser oriundos também de olivinas e óxidos de Fe e Ti, que são minerais comuns encontrados nos basaltos analisados na área em estu$\mathrm{do}^{7}$. Por um lado, o resíduo encontrado representa os minerais que ocorrem naturalmente nas rochas basálticas e, por outro, mostra que a pouca reação de dissolução observada nas superfícies dos resíduos (a maioria dos minerais apresentam-se sem corrosão) explica as baixas concentrações dos parâmetros químicos e de íons metálicos encontradoas nestas águas.

\section{Avaliação estatística da distribuição dos parâmetros de qualidade da água subterrânea}

Análise estatística foi aplicada às variáveis estudadas, com a finalidade de facilitar a interpretação dos dados obtidos. 
Tabela 5, Estatística descritiva das variáveis utilizadas

\begin{tabular}{|c|c|c|c|c|c|c|c|c|c|c|c|c|c|c|}
\hline \multirow{2}{*}{$\begin{array}{l}\text { variável } \\
\mathrm{Na}\end{array}$} & \multicolumn{2}{|c|}{$\begin{aligned} \text { poço } & 17 \\
\text { média } & \text { desvio } \\
& \text { padrão }\end{aligned}$} & \multicolumn{2}{|c|}{$\begin{array}{r}\text { poço } 19 \\
\text { média desvio } \\
\text { padrão }\end{array}$} & \multicolumn{2}{|c|}{$\begin{aligned} \text { poço } 20 \\
\text { média desvio } \\
\text { padrão }\end{aligned}$} & \multicolumn{2}{|c|}{$\begin{aligned} \text { poço } 36 \\
\text { média desvio } \\
\text { padrão }\end{aligned}$} & \multicolumn{2}{|c|}{$\begin{array}{r}\text { poço } 37 \\
\text { média desvio } \\
\text { padrão }\end{array}$} & $\begin{array}{l}\text { poço } \\
\text { média }\end{array}$ & \multirow{2}{*}{$\begin{array}{l}\begin{array}{l}\text { 38 } \\
\text { desvio } \\
\text { padrão }\end{array} \\
0,65\end{array}$} & \multicolumn{2}{|c|}{$\begin{aligned} \text { poço } & 39 \\
\text { média } & \text { desvio } \\
& \text { padrão }\end{aligned}$} \\
\hline & 49,30 & 0,80 & 10,25 & 1,34 & 10,64 & 0,93 & 7,15 & 0,14 & 12,85 & 0,15 & 10,17 & & 7,21 & 0,15 \\
\hline K & 0,09 & 0,02 & 0,38 & 0,06 & 1,04 & 0,03 & 0,07 & 0,01 & 0,20 & 0,01 & 0,38 & 0,03 & 1,09 & 0,06 \\
\hline $\mathrm{Ca}$ & 3,36 & 0,06 & 18,59 & 1,69 & 15,35 & 0,89 & 19,34 & 0,23 & 39,39 & 0,39 & 24,42 & 0,71 & 10,49 & 0,39 \\
\hline $\mathrm{Mg}$ & 0,03 & 0,01 & 4,50 & 0,25 & 2,48 & 0,03 & 6,67 & 0,14 & 10,40 & 0,37 & 7,62 & 0,28 & 2,64 & 0,03 \\
\hline $\mathrm{Cl}$ & 1,02 & 0,06 & 1,09 & 0,23 & 1,13 & 0,06 & 1,19 & 0,02 & 5,70 & 0,10 & 4,80 & 0,21 & 1,11 & 0,08 \\
\hline $\mathrm{HCO}_{3}$ & 100,99 & 0,34 & 83,36 & 1,10 & 64,96 & 0,36 & 87,73 & 0,06 & 156,28 & 0,12 & 104,32 & 0,40 & 46,02 & 0,18 \\
\hline $\mathrm{SO}_{4}$ & 1,34 & 0,60 & 1,13 & 0,01 & 0,66 & 0,02 & 2,03 & 0,09 & 5,37 & 0,33 & 2,64 & 0,18 & 0,73 & 0,02 \\
\hline F & 0,87 & 0,05 & 0,26 & 0,02 & 0,14 & 0,01 & 0,07 & 0,01 & 0,12 & 0,02 & 0,17 & 0,01 & 0,19 & 0,01 \\
\hline $\mathrm{NO}_{3}$ & 2,39 & 1,48 & 2,92 & 1,94 & 4,66 & 2,83 & 2,01 & 1,27 & 10,56 & 6,53 & 8,07 & 4,95 & 4,43 & 2,71 \\
\hline Temp $\mathrm{H}_{2} \mathrm{O}$ & 19,43 & 0,75 & 20,00 & - & 19,33 & 0,58 & 20,50 & 0,87 & 22,13 & 0,23 & 21,87 & 0,81 & 18,83 & 0,29 \\
\hline $\mathrm{pH}$ & 8,33 & 0,29 & 7,32 & 0,03 & 6,57 & 0,23 & 6,80 & - & 7,13 & 0,12 & 6,83 & 0,06 & 6,37 & 0,21 \\
\hline Condutividade & 204,33 & 2,31 & 178,83 & 16,87 & 140,20 & 8,94 & 176,13 & 2,59 & 333,33 & 2,31 & 228,33 & 11,50 & 107,07 & 3,00 \\
\hline STD & 98,67 & 2,52 & 79,30 & 8,93 & 67,50 & 1,32 & 85,00 & 6,08 & 162,00 & 10,58 & 110,67 & 11,37 & 52,00 & 1,73 \\
\hline $\mathrm{Fe}$ & 0,02 & 0,01 & 0,03 & 0,01 & 0,03 & 0,01 & 0,15 & 0,24 & 0,01 & 0,01 & 0,02 & 0,01 & 0,02 & 0,01 \\
\hline $\mathrm{Zn}$ & 0,02 & 0,01 & 0,12 & 0,02 & 0,14 & 0,02 & 0,78 & 0,38 & 0,28 & 0,42 & 0,69 & 0,25 & 0,46 & 0,40 \\
\hline
\end{tabular}

Dentre as 25 variáveis hidroquímicas estudadas, $15\left(\mathrm{Na}^{+}, \mathrm{K}^{+}\right.$, $\mathrm{Ca}^{2+}, \mathrm{Mg}^{2+}, \mathrm{Cl}^{-}, \mathrm{HCO}_{3}^{-}, \mathrm{SO}_{4}^{-}, \mathrm{F}^{-}, \mathrm{NO}_{3}^{-}$, $\mathrm{T}$ água, $\mathrm{pH}$, condutividade, $\mathrm{STD}, \mathrm{Fe}$ e $\mathrm{Zn}$ ) foram usadas na avaliação estatística por terem sido determinadas nas três campanhas de amostragem.

A Tabela 5 mostra as estatísticas descritivas das 15 variáveis. A estatística descritiva forneceu informações sobre as características das variáveis para cada poço. Através da análise da média pode-se constatar que o $\mathrm{NO}_{3}^{-}$no poço 37 está acima dos limites aceitos para a água potável ${ }^{23}$. Provavelmente o nitrato provém de fertilizantes. Os valores mais elevados das médias das variáveis $\mathrm{Na}^{+}$e $\mathrm{HCO}_{3}$ mostram que a água do poço 17 difere da dos demais poços. O sódio pode ser, provavelmente, devido a uma intrusão alcalina presente onde o poço 17 está perfurado. Já o bicarbonato pode estar relacionado a uma maior quantidade de calcita presente em fraturas.

Os resultados da ANOVA para poços mostraram que o ferro foi a única variável que não apresentou diferença significativa.

Na Figura 8 estão as comparações múltiplas de médias para os poços. Nas variáveis $\mathrm{Ca}^{2+}, \mathrm{Mg}^{2+}, \mathrm{Cl}^{-}, \mathrm{NO}_{3}^{-}$os poços 37 e 38 apresentaram médias significantemente maiores que os outros poços. Isto significa, provavelmente, no caso das três primeiras variáveis, que os íons são provenientes da dissolução dos minerais encontrados em basaltos e o nitrato é proveniente de fertilizantes. Para as variáveis $\mathrm{Na}^{+}, \mathrm{F}^{-}$e $\mathrm{pH}$ o poço 17 apresenta médias significantemente maiores que os demais poços (como já mencionado anteriormente o $\mathrm{Na}^{+}$deve ser devido à presença de uma intrusão alcalina) e o $\mathrm{F}^{-}$devido a presença de fluoritas em fraturas. $\mathrm{O}$ pH elevado pode estar relacionado com a presença de $\mathrm{CO}_{3}^{-}$na água e este pode ser oriundo de calcita normalmente encontrada em fraturas.

\section{CONCLUSÕES}

As análises dos íons maiores das águas subterrâneas na área estudada indicam que as mesmas pertencem a dois tipos químicos dominantes: águas bicarbonatadas sódicas (poço 17) e bicarbonatadas cálcicas para os demais poços. As observações das análises coletadas no decorrer do tempo sugerem que houve relativamente pequena mudança na qualidade das águas nos diferentes poços. A variabilidade espacial é fonte de variação dos dados mais importante que o fator temporal. Para a maioria dos poços a fonte dos íons maiores pode ser atribuída à dissolução dos minerais que compõem o basalto. $\mathrm{O} \mathrm{Na}^{+}$, por sua vez, pode ter sua origem atribuída a alguma intrusão
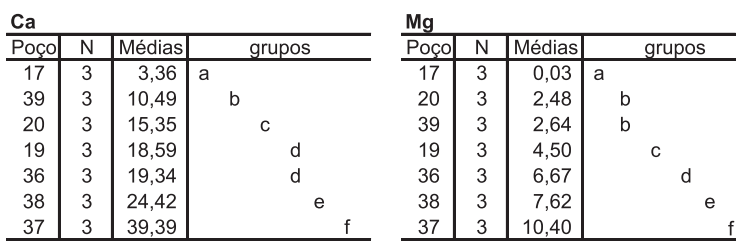

\begin{tabular}{|c|c|c|c|}
\hline \multicolumn{4}{|l|}{$\mathrm{Cl}$} \\
\hline Poço & $\mathrm{N}$ & Médias & grupos \\
\hline 17 & 3 & 1,02 & $a$ \\
\hline 19 & 3 & 1,09 & a \\
\hline 39 & 3 & 1,11 & a \\
\hline 20 & 3 & 1,13 & a \\
\hline 36 & 3 & 1,19 & a \\
\hline 38 & 3 & 4,80 & b \\
\hline 37 & 3 & 5,70 & \\
\hline
\end{tabular}

\begin{tabular}{|c|c|c|c|}
\hline $\mathrm{NO}_{3}$ & & & \\
\hline Poço & $\mathrm{N}$ & Médias & grupos \\
\hline \begin{tabular}{l|}
36 \\
\end{tabular} & 3 & 2,01 & $a$ \\
\hline 17 & 3 & 2,39 & a \\
\hline 19 & 3 & 2,92 & a \\
\hline 39 & 3 & 4,43 & $a \quad b$ \\
\hline 20 & 3 & 4,66 & $a b$ \\
\hline 38 & 3 & 8,07 & b \\
\hline 37 & 3 & 10,56 & s \\
\hline
\end{tabular}

\begin{tabular}{|c|c|c|c|}
\hline \multicolumn{4}{|l|}{$\mathrm{Na}$} \\
\hline Poço & $\mathrm{N}$ & Médias & grupos \\
\hline \begin{tabular}{l|l}
36 \\
\end{tabular} & 3 & 7,15 & $a$ \\
\hline 39 & 3 & 7,21 & a \\
\hline 38 & 3 & 10,17 & b \\
\hline 19 & 3 & 10,25 & b \\
\hline 20 & 3 & 10,64 & b \\
\hline 37 & 3 & 12,85 & c \\
\hline 17 & 3 & 49,30 & d \\
\hline
\end{tabular}

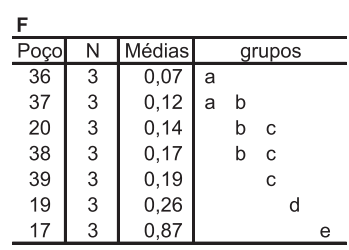

\begin{tabular}{|c|c|c|c|c|c|}
\hline & & Tiverios & \multicolumn{3}{|c|}{ grupos } \\
\hline 39 & 3 & \begin{tabular}{|l|}
6,37 \\
\end{tabular} & $a$ & & \\
\hline 20 & 3 & 6,57 & a & & \\
\hline 36 & 3 & 6,80 & a & b & \\
\hline 38 & 3 & 6,83 & a & b & c \\
\hline 37 & 3 & 7,13 & & & c \\
\hline 19 & 3 & 7,32 & & & c \\
\hline 17 & 3 & 8,33 & & & d \\
\hline
\end{tabular}

Médias seguidas de mesma letra não diferem significativamente

Figura 8. Variações múltiplas de variáveis entre os poços

alcalina já que no basalto o feldspato alcalino, que poderia originar este íon, ocorre somente na mesóstase. As baixas concentrações dos íons metálicos dificulta a determinação de sua origem que poderá ser natural (proveniente da dissolução de minerais) ou antropogênica (efluentes ou sub-produtos de atividades agropecuárias).

$\mathrm{O}$ aumento da concentração de nitrato na $3^{\mathrm{a}}$ campanha, principalmente nos poços 37 e 38 , acima dos valores permitidos para o consumo humano estabelecidos na Portaria 1469/2000 é, provavelmente, devido às práticas agropecuárias na região (agricultura e suinocultura). Uma vez que já estão sendo detectadas concentrações anômalas de nitrato nas águas subterrâneas, a tendência é que as águas superficiais também apresentem elevadas concentrações 
de nitrato e, conseqüentemente, de outras substâncias, por exemplo, o fosfato. É importante que os programas de monitoramento das águas superficiais e subterrâneas associados à implantação das hidrelétricas, contemplem uma avaliação deste parâmetro e de outros pertinentes, associados à detecção de contaminação orgânica, a fim de que possam ser previstos mecanismos de controle/ mitigação.

\section{AGRADECIMENTOS}

Ao técnico da Fundação Estadual de Proteção Ambiental C. Peixoto pelo apoio à realização das amostragens. Ao $\mathrm{CNPq}$, FAPERGS, FEPAM pelo suporte financeiro. Ao CME/UFRGS pelas análises ao MEV. Ao Prof. Dr. M. L. L. Formoso pela revisão do texto.

\section{REFERÊNCIAS}

1. Tressoldi, M.; Celestino, T. B.; Costa, S. M. K. M.; Vicenzo Jr., M. C. de; Anais do $6^{\circ}$ Congresso Brasileiro de Geologia/IX COBRAMSEF, Salvador, Brasil, 1990

2. Tressoldi, M.; Costa, S. M. K. M. Vicenzo Jr., M. C. de; Anais do $6^{o}$ Congresso Brasileiro de Geologia/IX COBRAMSEF, Salvador, Brasil, 1990.

3. Albuquerque Filho, J. L.; Bottura, J. A.; Borin Júnior, T.; Corrêa, W. A. G; Anais do Congresso Brasileiro de Águas Subterrâneas, Recife, Brasil,1994.

4. Silva, A. L. B.; Albuquerque Filho, J. L.; Breviglieri, F. C.; Filipov, M.; Soares, L; 8th International IAEG Congress/ 8ème Congrés International de AIGI, Balkema, Rotterdam, 1998.

5. Ellis, P. A.; Rivett, M. O.; Mackay, R.; Geophysical Research Abstracts 2003, 5, 12063.

6. CEEE, Superintendência de Geração Hidrelétrica; Inventário hidrelétrico: Bacia Taquarí-Antas, Porto Alegre, Brasil, 1997.
7. Comim-chiaramonti, P.; Bellieni, G.; Piccirillo, E. M.; Melfi, A. J. Em The Mesozoic volcanism of the Paraná Basin: petrogenetic and geophysical aspects; Piccirillo, E. M.; Melfi, A., eds.; IAG-USP: Brazil, 1988, cap. 3.

8. Gomes, M. E. B.; Tese de Doutorado, Universidade Federal do Rio Grande do Sul, Brasil, 1996.

9. Scopel, R. M.; Tese de Doutorado, Universidade Federal do Rio Grande do Sul, Brasil, 1997.

10. Schenato, F.; Tese de Doutorado, Universidade Federal do Rio Grande do Sul, Brasil, 1997.

11. Hausman, A.; Acta Geológica Leopoldensia 1995, Série Mapas, 2.

12. CERAN/ENGEVIX/DESENVIX; Estudo de Impacto Ambiental: complexo energético rio das Antas, Porto Alegre, Brasil, 2000.

13. Magna Engenharia; Avaliação quali-quantitativa das disponibilidades e demandas de água na Bacia Hidrográfica do Sistema Taquarí-Antas: relatório final (RF); síntese dos estudos, Porto Alegre: Governo do Estado do Rio Grande do Sul / CRH/RS / Secretaría das Obras Públicas e Saneamento / DRHS / FRH, Porto Alegre, Brasil, 1997.

14. CERAN - Complexo Energético Rio das Antas; Mapeamento dos aquíferos ocorrentes na área de influência da UHE Monte Claro, CERAN, Porto Alegre, Brasil, 2001.

15. ABNT - Associação Brasileira de Normas Técnicas; NBR 9898, Rio de Janeiro, Brasil, 1987.

16. APHA, AWWA, WEF; Standard methods for the examination of water and wastewater, $18^{\text {th }}$ ed., Washington, 1992.

17. Stumm, W.; Morgan, J. J.; Aquatic chemistry: chemical equilibria and rates in natural waters, Jonh Wiley \& Sons, Inc.: New York, 1996, p. 1022.

18. Ure, A. M.; Davidson, C. M.; Chemical speciation in the environment, Blackie Academica \& Professional: London, 1995, p. 408.

19. Salbu, B.; Steinnes, E., eds.;Trace elements in natural waters, CRC: Florida, 1995.

20. Meunier, A.; Argiles; GB Science Publisher: France, 2003, p. 453.

21. Banks, D.; Reimann, C. ; Appl. Geochem. 1995, 10,117.

22. http://www.comsats.org.pk/latest/niaz.pdf, acessada em Outubro 2003.

23. Brasil - Ministério da Saúde; Portaria 1469/2000.

24. Li, H. ; Misawa, S.; Environ. Geol. 1994, 24, 234

25. Davis, J. A.; Kent, D. B.; Rea, B. A.; Maest, A . S.; Garabedian, S. P. Em Metals in Groundwater; Allen, H.; Perdue, E. M.; Brown, D. S., eds.; Lewis Publishers: Chelsea, 1993, cap. 8. 